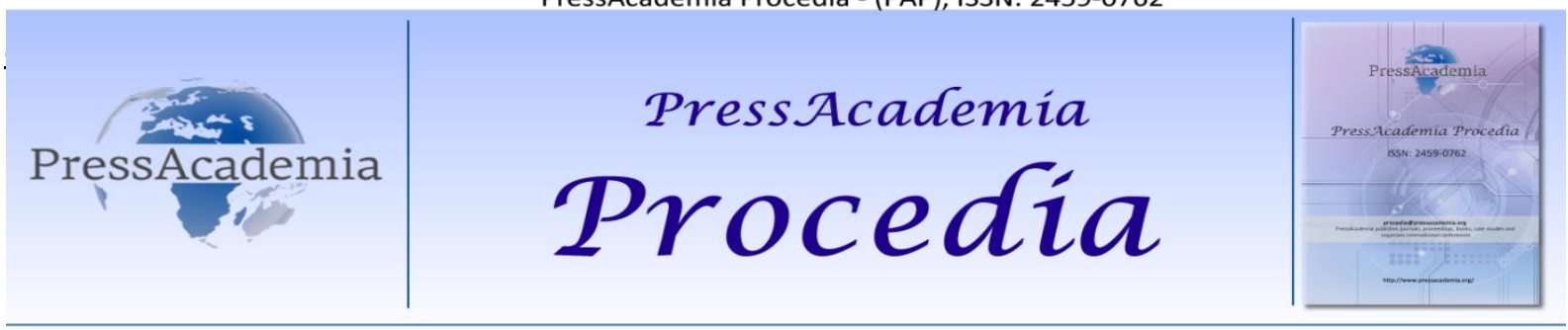

Global Business Research Congress (GBRC), May 24-25, 2017, Istanbul, Turkey.

\title{
ANALYSIS OF THE OCCUPATIONAL HEALTH AND SAFETY FACTOR IN BUSINESS ENTERPRISES FROM THE VIEWPOINT OF EMPLOYEES
}

\author{
DOI: 10.17261/Pressacademia.2017.434 \\ PAP-GBRC-V.3-2017(49)-p.495-499
}

Mehmet Colak ${ }^{1}$, Tahsin Cetin ${ }^{2}$

${ }^{1}$ Muğla Sıtkı Koçman University, Technology Faculty, Kötekli Campus, Muğla, Turkey. Email: $\underline{\text { cmehmet@mu.edu.tr }}$

${ }^{2}$ Muğla Sıtkı Koçman University, Technology Faculty, Kötekli Campus, Muğla, Turkey. Email: tahsincetin@mu.edu.tr

To cite this document

Çolak, M., Çetin, T., (2017). Analysis of the occupational health and safety factor in business enterprises from the viewpoint of employees, PressAcademia Procedia (PAP), V.3, p.495-499.

Permemant link to this document: http://doi.org/10.17261/Pressacademia.2017.434

Copyright: Published by PressAcademia and limited licenced re-use rights only.

\begin{abstract}
There are many studies aiming to reveal the reasons of workplace accidents. According to these studies, workplace accidents occur due to a number of reasons. It is known that workplace accidents generally occur due to the industrialization way of countries, business models, insufficiency of accident statistics and investigations, lack of inspection services, qualities of employees and lack of occupational safety consciousness. The reasons of workplace accidents may show both general and national-specific properties. Business enterprises in our country are generally small and medium scaled enterprises and the lack of occupational safety organization, training and inspection increases workplace accidents. Today, professional ethics, ethical values, occupational health and safety at workplaces are the most important factors in terms of today's sense of business. Besides, the development of a country depends on the protection and efficient use of man power, natural resources, all kinds of machines-equipments and technical man power. As a matter of fact, evaluating the data of the answers given by business employees in this questionnaire; majority of participants stated that occupational health and safety applications at workplaces had a positive effect upon the productivity and quality of workplaces and forming a social perception on this issue would be useful for future employees; however, the inspections remained insufficient.
\end{abstract}

Keywords: SME businesses, employee perception, business security factor, risk, ergonomics.

JEL Codes: J28, 110, J20

\section{IŞLETMELERDE IŞ SAĞLIĞı VE GÜVENLIĞi FAKTÖRÜNÜN ÇALIŞANLAR BAKIMINDAN ANALIZi}

\section{ÖZET}

Is kazalarının nedenlerini ortaya koymaya yönelik olarak birçok araştırma yapılmıştır. Yapılan araştırmalara göre, iş kazalarının meydana gelmesinde birden çok nedenin etkisi bulunmaktadır. İş kazaları genellikle ülkelerin sanayileşme biçiminden, işletme şekillerinden, kaza istatistik ve araştırmalarının yetersizliğinden, denetim hizmetlerinin eksikliğinden, çalışanların niteliklerinden ve iş güvenliği bilincinin olmamasından kaynaklandığı bilinmektedir. İş kazalarının nedenleri genel özellikler göstermekle birlikte, ülkelere göre kendine özgü bazı özelliklerde gösterebilmektedir. Ülkemizdeki işletmeler genellikle küçük ve orta ölçekli işletmeler olmakla birlikte, iş güvenliği organizasyonu, eğitim ve denetimi istenilen düzeyde olmaması, iş kazalarını arttırıcı bir etki yapmaktadır. Günümüzde iş yerlerinde, iş ahlakı, etik değerler ve günümüz işletme anlayışı bakımından iş sağlığı ve güvenliği her şeyin önünde gelmektedir. Ayrıca bir ülkenin gelişmesi; insan gücünün, doğal kaynakların, her türlü makine-techizatın ve teknik ve teknik insan gücünün korunmasına, aynı zamanda etkili ve verimli bir şekilde kullanılmasına bağlıdır. Nitekim işletme çalışanlarına yönelik yapılan bu anket çalışmasında alınan cevapların verileri değerlendirildiğinde, katılımcıların çoğunluğu iş yerindeki iş sağlığı ve güvenliği uygulamalarının o iş yerindeki iş verimini ve kaliteyi olumlu etkilediğini, bu konuda toplumsal bir algı oluşturmanın gelecek nesilde çalışan konumunda olacaklara fayda sağlayacağı fakat denetimlerin yetersiz olduğu bulgularımız arasındadır.

Anahtar Kelimeler: КОВі işletmeleri, çalışan algısı, iş güvenliği faktörü, risk, ergonomi JEL Kodları: J28, I10, J20 


\section{GíRiş}

Gelişen endüstrileşme ve sanayileşmeyle birlikte iş sağlığı ve güvenliği konusunda da bazı çalışmaları zorunlu kılmıştır. Işletmelerin, tüm üretim aşamalarında meydana gelecek olumsuzlukları ortadan kaldırabilmeleri için iş sağlığı ve güvenliği bakımından uygulayacakları korunma ve önleme politikalarına bağlı olduğu gerçeğidir.

İş sağlığı ve güvenliği çalışmalarını gerçekleştirmemekten kaynaklanan iş kazaları ve meslek hastalıkları sonucu ortaya çıkan görünen görünmeyen maliyetler; önleme için yapılan yatırımlardan çok daha yüksektir. Sosyal güvenlik açısından temel önemde olan, en iyi tazminat ve iyileştirme programları bile işle ilgili kaza veya hastalıklardan kaynaklanan yaşam kalitesi kaybını karşılayamamaktadır.

\section{LITERATÜR INCELEMESI}

Küreselleşen dünya pazarında hızla artan ve artmaya devam eden, işletmeler arası rekabetin sonucunda temel üretim faktörlerinden biri olan insan faktörünün önceki yıllara oranla daha fazla önem kazandığı gözlenmektedir. Bu yoğun rekabetle baş edebilmek için insan faktörünü merkeze alan yönetim anlayışlarının gelişmesi vesilesiyle insana ait iş güvenliği, iş sağlığı, iş doyumu gibi kavramlar önem kazanmıştır (Yıldırım ve diğ., 2015).

Yaşamının önemli bir kısmını iş yerinde geçiren insanın, buradaki güvenlik ihtiyacını karşılamak amacıyla, işçi sağlığı ve iş güvenliği adı altında bazı sistematik çalışmalar yürütülmüş ve işçi sağlığı ve iş güvenliği, disiplinler arası bir kavram ve çalışma alanı olarak tüm dünyaya yayılmıştır. Dünya'da iş kazası ve meslek hastalıklarından kaynaklanan kaybedilen yaşamlar düşünüldüğünde, işçi sağlığı ve iş güvenliği hakkındaki çalışmaların ve bu konuda gerçekleştirilmesi gereken ilerlemenin önemi gözler önüne serilmektedir (Uslu, 2014).

Aydın vd. (2012) iş sağlığını "bütün çalışanları bedensel, ruhsal ve sosyal yönden en yüksek düzeye getirmeyi, bu düzeyi sürdürmeyi, bu düzeyi bozacak etkenleri önlemeyi, çalışanları fizyolojik ve psikolojik yeteneklerine uygun işlere yerleştirmeyi ve böylece işi insana, insanı işe adapte etmeyi amaçlayan bir alan" olarak tanımlarken, iş güvenliğinin ise "iş yerlerini işin yürütümü nedeniyle oluşan tehlikelerden uzaklaştırmak ve sağlığa zarar verebilecek koşullardan arındırarak, daha iyi bir çalışma ortamı sağlamak için yapılan sistemli çalışmalar" olduğunu vurgulamıştır.

İ̧ kazalarına ilişkin yukarıdaki veriler ve ülkemizde yaşanan iş kazaları, meslek hastalıkları, sürekli iş görmezliğe sebep olan vakalar ve ölümlü kaza vakalarının Dünya ve Avrupa'yla karşılaştırmalı sonuçları doğrultusunda, ülkemizdeki iş kazası ve meslek hastalıkları konusundaki çalışmaların yetersiz kaldığı öne sürülebilir.

Bir işletmede yaşanan kazadan; kazaya maruz kalan çalışanlar ve yakınları, kazaya sebep olan çalışanlar, kazaya tanık olanlar, işletme bünyesinde kazayı duyan çalışanlar, işletme, çevre işletmelerin çalışanları, işletmenin müşterileri, işletme için çalışan taşeron firmalar olumsuz etkilenmektedir. Ayrıca iş kazası ile ilgili olarak devletçe yapılan soruşturma, yaralanan veya sakat kalan iş görenin rehabilitasyonu, iş görenin bir süre veya tamamen üretim elemanı olmaktan çıkması ve tüketim elemanı olması, ülke ekonomisini dolaylı etkilemektedir (Kurt, 1998).

Türkiye'de yaşanan iş kazaları değerlendirildiğinde; Türkiye'nin Dünya'da en çok iş kazasının yaşandığı üçüncü ülke, Avrupa'da ise birinci ülke olduğu görülmekte ve bu konuda gerçekleştirilen çalışmaların diğer ülkelere kıyasla yetersiz olduğu açığa çıkmaktadır (Yıldırım ve diğ., 2015).

Türkiye'de iş̧̧i sağlığı ve iş güvenliği eğitimlerindeki bilgi yetersizliği, verilen kurumsal bilgilerin davranışa dönüşmemesi ve iş güvenliği eğitimindeki süreksizlik verilen eğitimin kalıcı olmasındaki en önemli engellerdir (Aydın vd., 2010).

Yönetici pozisyonunda olmayan çalışanlar da yaptıkları işlerle ilgili olarak aldıkları eğitim doğrultusunda bilinçli, tedbirli, disiplinli davranmalı, moral bozukluğu ve yorgunluk içinde bulunmamalı, her şeyden önce kendi hayatına ve sağlığına önem vermeli, işyerlerinde emniyetle çalışmalarından daha önemli bir şey olmadığını ve işin bitiminden sonra kendilerini evde bekleyenlerin olduğunu unutmamalıdır (Çelikdin, 1999).

Kazaların ve meslek hastalıklarının önlenmesine yönelik bahsedilen çalışmalarda, işletmelerde kişilerin konu hakkında alması gereken sorumluluk ve yükümlülükler, şirket politikası ve yönetmeliğinde bahsedilebileceği gibi aynı zamanda gerekli kanun, tüzük ve mevzuat düzenlemeleri aracılığıyla devlet tarafından da belirlenir.

Devletin, iş̧̧i sağlığı iş güvenliği hakkında gerçekleştirdiği yasal düzenlemelerin yanında yol gösterme, ikaz etme, eğitim, denetleme, araştırma gibi fonksiyonlarını ÇSGB bünyesinde gerçekleştirmesi, yaşanabilecek kazaların önüne geçmede etkili olmaktadır (Çelikdin, 1999).

İş kazaları ve meslek hastalıkları, sadece işletmeyi değil aynı zamanda bu kaza ve hastalıklara maruz kalan çalışanları ve aileleri ile sosyal çevrelerini de kuşatır ve toplum bütünüyle üretim sürecinin bu negatif sonuçlarıyla ilgilenmek zorunda kalır. 
Iş kazası ve meslek hastalıklarını azaltmanın yollarından biri, işverenlerin konuya ilişkin yükümlülükleri ve sorumlulukları hakkında yeterli bilgi sahibi olmalarıdır. İşverenler, yükümlülüklerini yerine getirdikleri takdirde hem iş kazası ve meslek hastalıklarında önemli bir azalma olacak, hem de söz konusu kaza ve hastalık hallerinde idari, cezai ve hukuki yaptırımlarla karşılaşmayacaklardır ( Baycık, 2007).

Yeni teknoloji, yeni üretim teknikleri, daha kompleks makineler ve rekabet ortamı, yeni yatırım ve araştırmaları gerekli kılmaktadır. Bu nedenle bu yatırımlardan maksimum yarar sağlanması için vardiya sistemi gündeme gelmektedir. Vardiya sistemi gece çalışmalarını zorunlu kılmakta ve gece çalışmaları sağlık ve sosyal yönden çalışanları daha çok hırpalamaktadır. Bunun sonucunda birçok sanayi kolunda devamsızlık ve işi bırakma eylemleri, işgücü devir hızının yüksekliği gibi sorunlar ekonomik açıdan önemli maliyet artışlarına ve konuya çözüm arama yönünde daha çok çaba harcanmasına neden olmaktadır ( Gerek, 1998).

Çalışanların yaşam kesitlerinin önemli bir kısmı işyeri ortamında geçmektedir. İş kazalarıyla karşılaşan kişiler iş güçlerinin tümünü veya bir kısmını belirli bir süre yitirmektedirler. Bunun, ücret gelirinin tümünün ya da bir bölümünün sürekli ya da belirli bir süre ile yitirilmesi anlamına geleceği açıktır. Kaza geçirinceye kadar üretken olan işçi, artık tüketici ve belki de başkalarına muhtaç hale gelmiştir ( Gerek, 1998).

\section{VERI VE YÖNTEM}

İş sağlığı ve iş güvenliği kapsamında yürürlükte olan kanun ve gerek ülke genelinde gerekse lokal bazda yapılan daha önceki ampirik araştırmalardan yararlanılarak oluşturulan anket formu yardımıyla veriler elde edilmiştir. Çalışma kapsamında kullanılan anket formu demografik değişkenleri ölçmek için 8 soru ve öğrenci yaklaşımlarını, algılarını, tutumlarını ölçmek için oluşturulan $3^{\prime}$ lü Likert ölçeği ile 16 soru yöneltilmiştir. Anket uygulamasında ki ölçek soruları daha önce bu alanla ilgili yapılmış çalışmalardan da esinlenerek hazırlanmıştır.

\section{BULGULAR VE TARTISSMA}

Elde edilen veriler istatistik programı ile analiz edilmiş ve aşağıdaki grafiklerle gösterilip yorumlanmıştır.

\section{Tablo 1: Katılımcıların Demografik Bilgileri}

1- Katılımcıların Cinsiyetleri;

2- Katılımcıların Yaş Ortalaması;

\section{3- Çalışılan bölüm ve birimler;}

a) Bay

b) Bayan

\section{Sayı}

61

15
Yüzde

80

20

$\begin{array}{lll}\text { a) 18-24 yaş arası } & 20 & 30 \\ \text { b) 25-40 yaş arası } & 30 & 45 \\ \text { c) 41 ve üzeri yaş } & 16 & 25\end{array}$

a) Üretim $\quad 45 \quad 59$

b) Montaj $\quad 7 \quad 9$

c) Sevkiyat $\quad 5 \quad 7$

d) Diğer $\quad 19$

4- Bulunduğunuz işyerinde kaç yıldır çalışıyorsunuz?

$\begin{array}{lll}\text { a) } 1-3 \text { yıl } & 41 & 54 \\ \text { b) } 4-10 \text { yıl } & 28 & 37 \\ \text { c) 11-20 yıl } & 5 & 6 \\ \text { d) } 21 \text { ve üstü } & 2 & 3\end{array}$

5- Çalışma süresi içerisinde İş Sağlığı ve Güvenliği (iSG) eğitimi aldınız mı?

$\begin{array}{lll}\text { a) Evet } & 62 & 82 \\ \text { b) Hayır } & 14 & 18\end{array}$

6- Çalışma yerinde İş Kazası veya Meslek hastalığıyla karşılaştınız mı?

$\begin{array}{lll}\text { a) Evet } & 23 & 30 \\ \text { b) Hayır } & 53 & 70\end{array}$

7- Çalışma yerinde düzenli olarak isG ile ilgili bilgilendirme toplantıları uygulamalı yapıldı mı?
a) Evet
40
53
b) Hayır
36
47

DOI:10.17261/Pressacademia.2017.434 
8- Çalıştığınız iş yerinde yeni bir araç veya ekipman alındığında doğru bir şekilde nasıl kullanılacağı hakkında uygulamalı bir eğitim verildi mi?
a) Evet
39
b)Hayır
37
49

Tablo 2: Çalışılan Yerde İş Sağlığı ve Güvenliği Konusunda Yönetsel Önlem ve Tedbirler

1- İşletmemizde çalışanlara sağlık ve güvenlik ile ilgili Kişisel Koruyucu Donanımlar (KKD) sağlanır.

2- İşletmemiz de sağlık ve güvenlik ile ilgili tedbirlere uyulup uyulmadığı denetlenir.

3- İşletmemizde sağlık ve güvenlik ile ilgili gerekli tedbirler alınır.

(\%) 1-Katılıyorum 2- Kararsızım 3- Katılmıyorum

4- İşletmemizde sağlık ve güvenlik için gerekli olan teknik ekipmanlar bulunur.

56

43

51

50

34

35
6

17

9

9

20

22
14

16

16

17

22

19

Tablo 3: Çalışanların İş Sağlığı ve Güvenliği Kriterlerine Göre Çalışması

1-Çalışma arkadaşlarım işyerinde sağlık ve güvenlik

(\%) 1-Katılıyorum 2- Kararsızım 3- Katılmıyorum bakımından bir tehdit ile karşılaştıklarında derhal İsyeri yönetimine haber verirler

47

31

36

35

29

31
16

21

15

23

24

20
24

25

Koruyucu Donanımları (KKD) doğru bir şekilde kullanırlar

Tablo 4: Çalışanların İ̧̧ Sağıı̆ı ve Güvenliği Konusundaki Farkındalık Seviyeleri

(\%) 1-Katılıyorum 2- Kararsızım 3- Katılmıyorum

1- Çalışma arkadaşlarım, meslek hastalıkları ve nedenleri hakkında bilgi sahibidir.

21

17

20

29
21

23

22

12
33

36

34

35 


\section{SONUÇ}

Bütün bu çalışmaların yanı sıra firmaların güçlü bir iş güvenliği kültürünü inşa ederek benimsemesi yaşanabilecek iş kazaları ve meslek hastalıklarının önlenmesinde etkili olacaktır.

İş sağığı ve güvenliğinin küresel düzeydeki önemi, iş kazalarının ortaya çıkardığı sonuçların sadece kazaya uğrayan ailesi, çalıştığı işletme ülke ekonomisi ve yaşadığı toplumla sınırlı bir etkiye sahip olmayıp; küreselleşen dünyada küresel bir etki ve boyut da taşıdığı gerçeğinde görülebilmektedir (Demirbilek, 2005).

Günümüzde, daha iyi çalışma standartları ve teknolojik gelişmelere rağmen, iş kazaları ve meslek hastalıkları dünya genelinde artmasının; sanayileşmiş ülkelerdeki emek yoğun sanayi üretiminin, emeği ucuz ve sosyal koruma düzeyi düşük gelişmekte olan ülkelere kaydırılmasının neden olduğu öngörülebilir.

\section{KAYNAKLAR}

Aydın, U., Karaca, N.G., Özgüler, V.C., Karaca, E., Güngör, Y. ve Demir, M. (2012). "Türkiye'de İş Sağlığı ve Güvenliği Eğitiminin İş Kazaları ve Meslek Hastalıklarının Önlenmesindeki Rolü", Anadolu Üniversitesi Bilimsel Araştırma Projesi.

Uslu, V., İşletmelerde İş Güvenliği Performansı Ve İş Güvenliği Kültürü Algılamaları Arasındaki İlişki: Eskişehir illi Metal Sektöründe Bir Araştırma, Eskişehir Osmangazi Üniversitesi, Sosyal Bilimler Enstitüsü, Yüksek Lisans Tezi, Eskişehir.

Kurt, M. (1998), “Ergonomi ve İş Güvenliği”, Tudev İş Dünyası Dergisi, Sayı: 1, Yıl: Mart-Nisan 1998, ss. 15-17.

Çelikdin, B. (1999). “iş̧̧̧i Sağlığı ve İş Güvenliği İş Kazalarının Önlenmesi”, TUDEV İş Dünyası Dergisi, Sayı:6, Yıl:1999, s. 16-18.

Gaye Baycık, İş Sağlığı ve Güvenliği Bildiriler Kitabı(İnşaat İşyerlerinde İşverenin İSG Yükümlülükleri ve Sorumluluğu), İstanbul: İMO Yayını, Ekim 2007, s. 41.

Tunç Demirbilek, İş Güvenliği Kültürü (Kültür), 1.Basım, İzmir: Dokuz Eylül, 2005.

Nüvit Gerek, Türkiye'de İşçi Sağığı ve İş Güvenliği, Ankara: Türk Metal Sendikası Yayınları, 1998.

İbrahim YILDIRIM, Kadri Cemil AKYÜZ, Aytaç AYDIN, Cumhur ALEVLi, 2015, Akdeniz Bölgesi Orman Ürünleri Sanayi Çalışanlarının İş Güvenliği Algılarının Belirlenmesi, Mühendislik Bilimleri ve Tasarım Dergisi, 3(3), ÖS:Ergonomi2015, 213-222, 2015 ISSN: 1308-6693, Süleyman Demirel Üniversitesi, Isparta.

Camkurt, M.Z., 2007. İşyeri Çalışma Sistemi Ve İşyeri Fiziksel Faktörlerinin İş Kazaları Üzerindeki Etkisi, TÜHis İş Hukuku ve İktisat Dergisi Cilt: 20 Sayı: 6 , Cilt: 21 Sayı: 1 Mayıs / Ağustos 2007.

Gedik, T., ve İlhan, A., 2014. Sakarya ili mobilya imalatçılarında iş sağlığı ve iş güvenliği üzerine bir inceleme, SDÜ Orman Fakültesi Dergisi, Sayı: 15/123-129, Isparta.

Standart Kalite, 2013. OHSAS 18001 İş sağlığı ve güvenliği yönetim sistemi. http://www.standartkalite.com/ohsas 18001_nedir.htm, Erişim: 08.12.2016

Özkılıç, Ö., 2005. İş Sağlığı ve Güvenliği Yönetim Sistemleri ve Risk Değerlendirme Metodolojileri; TísK Akademi Yayınları, Ankara. 